EESTI NSV TEADUSTE AKADEEMIA TOIMETISED. KEEMIA

ИЗВЕСТИЯ АКАДЕМИИ НАУК ЭСТОНСКОИ ССР, ХИМИЯ

PROCEEDINGS OF THE ACADEMY OF SCIENCES OF THE ESTONIAN SSR. CHEMISTRY

$1989,38,1$

УДК 661.632.12.069.85(474)

Э. ААСАМЯЭ, Вера СААР

\title{
О ПЕНООБРАЗОВАНИИ ПРИ АЗОТНОКИСЛОТНОМ РАЗЛОЖЕНИИ ФОСФОРИТОВ ПРИБАЛТИКИ
}

\author{
(Представил М. Вейдерма)
}

При производстве нитрофоски на первой стадии процесса происходит азотнокислотное разложение апатитового концентрата [1,2]. Представляет интерес изучить в этом плане процесс получения нитрофоски из кингисеппских и маардуских фосфоритных концентратов. Значительная доля последних перерабатывается на фосфоритную муку, агрохимическая эффективность которой довольно низка $\left[{ }^{3}\right]$.

Процесс разложения оболовых фосфоритов азотной кислотой сопровождается интенсивным вспениванием реакционной смеси, что уменьшает полезный объем реакторов $\left.{ }^{4,5}\right]$. Вспенивание вызвано выделением в газовую фазу $\mathrm{CO}_{2}$, оксидов азота, фтористых газов, паров $\mathrm{HNO}_{3}$ и $\mathrm{H}_{2} \mathrm{O}\left[{ }^{6-8}\right] . \mathrm{CO}_{2}$ образуется при разложении фосфатного минерала, близкого по составу к франколиту [ $\left.{ }^{9}\right]$, карбонатных минералов и органического вещества $[6,7]$. Оксиды азота выделяются в результате взаимодействия азотной кислоты с органическим веществом и с некоторыми минеральными примесями, главным образом с пиритом $\left[{ }^{6,7,10}\right]$. Для разрушения пены нами ранее использовался рекомендованный Научноисследовательским институтом по удобрениям и инсектофунгицидам [11] сукцинол $[5,12]$. Установлено также, что и карбамид, добавляемый для уменьшения выделения оксидов азота, способствует подавлению пенообразования $\left[{ }^{12}\right]$.

Имеются сведения о закономерностях пенообразования при азотнокислотном разложении фосфорита Каратау $\left[{ }^{13}\right]$, относительно же переработки фосфоритов Прибалтики аналогичные данные отсутствуют.

Задачей настоящего исследования было изучение влияния состава фоссырья, технологических параметров процесса, а также добавок сукцинола и карбамида на пенообразование при азотнокислотном разложении фосфоритных концентратов ряда месторождений Прибалтики.

Для определения вспениваемости реакционной пульпы фосфорит $(10$ г) разлагали азотной кислотой в мензурке объемом 500 мл в течение 5 мин, периодически замеряя в ходе опыта объем реакционной массы, а потом и объем пульпы без пены, Концентрация кислоты $(C)$ составляла $50 \%$, ее количество $(N)-100 \%$ от стехиометрической нормы, рассчитанной по содержанию $\mathrm{CaO}$ в фосфорите, начальная температура $-50^{\circ} \mathrm{C}$. Дозирование фосфорита проводили в течение секунды, пульпу перемешивали с помощью механической мешалки (длина лопасти 40 мм, скорость вращения 540 об/мин).

В экспериментах использовали флотационные концентраты фосфорита четырех типов $\left[{ }^{14}\right]$, а также пробы хибинского и ковдорского апатитовых концентратов (таблица). Фосфоритные концентраты содержали $26,9-30,9 \% \quad \mathrm{P}_{2} \mathrm{O}_{5}$ и существенно различались по содержанию пирита $(0,2-3,7 \%)$ и карбонатных минералов $(1,7-15,2 \%$ в пересчете на доломит). 
Характеристика фосфатного сырья̆

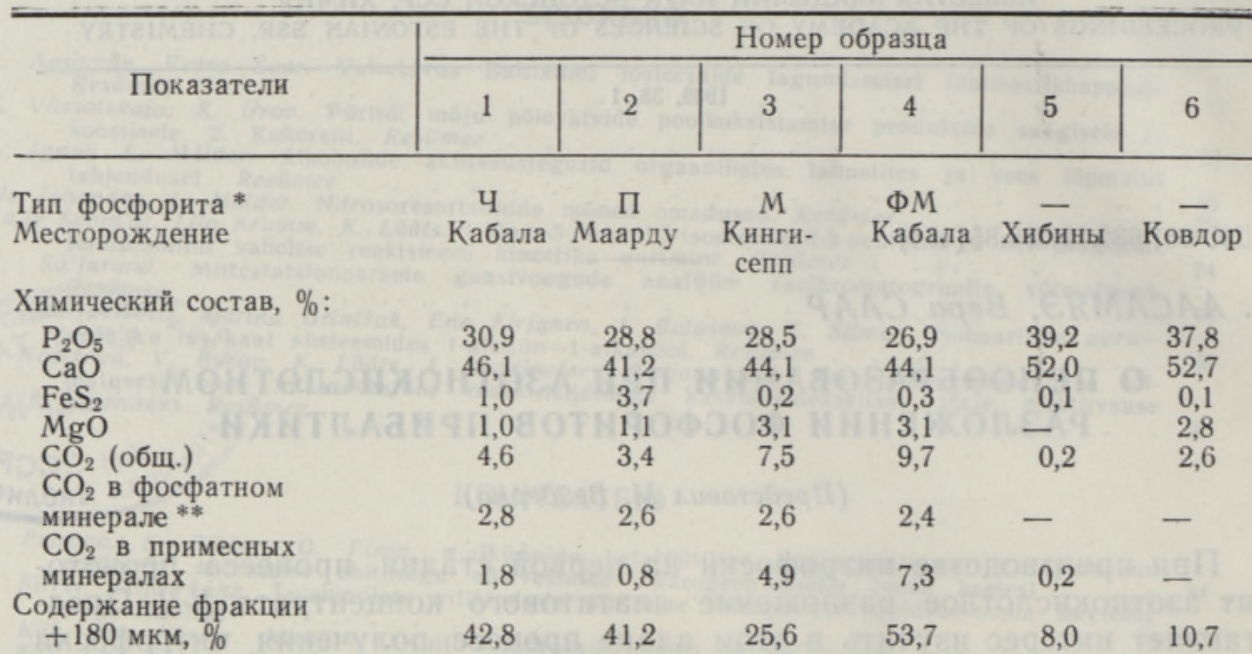

* Обозначения для типов фосфорита: Ч - чистый, П - пиритовый, $\mathrm{M}$ - магнезиальный, $Ф$ - ферроидно-магнезиальный.

** Расчетные данные с учетом отношення $\mathrm{CO}_{2}: \mathrm{P}_{2} \mathrm{O}_{5}$ в фосфатном минерале, равном $0,09\left[{ }^{9}\right]$.

Эксперименты определения вспениваемости по вышеуказанной методике показали, что при азотнокислотном разложении хибинского апатита пенообразования не происходит. В опыте с ковдорским апатитом пены выделялось мало и разрушалась она быстро - в течение 5-10 с (рис. 1). Взаимодействие фосфоритов с азотной кислотой сопровождалось значительно более интенсивным вспениванием, независимо от типа

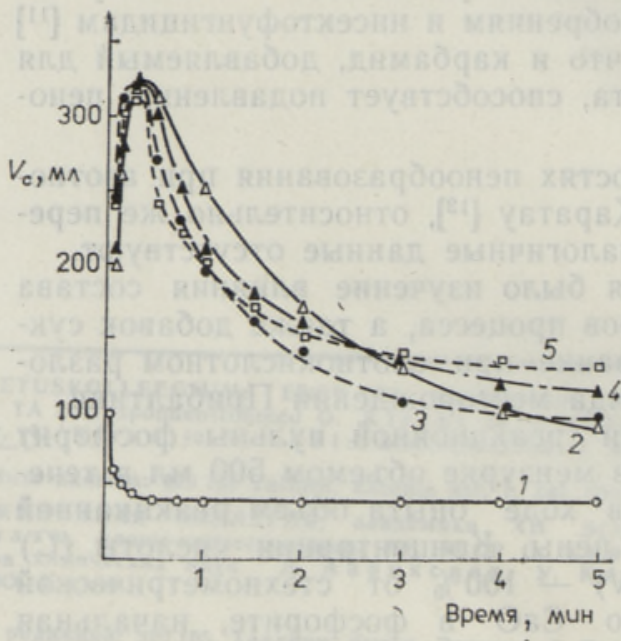

Рис. 1. Зависимость объема реакционной смеси $\left(V_{\mathrm{c}}\right)$ от времени разложения ковдорского апатита $(I)$, кингисеппского фосфорита магнезиального типа (2), кабалаского фосфорита чистого типа (3), кабалаского фосфорита ферроидно-магнезиального типа (4), маардуского фосфорита пиритового типа (5). $N-100 \%$ стех., $C-$ $50 \%, T-50^{\circ} \mathrm{C}$; навеска фосфатного сырья 10 г (здесь и на рис. 3-6).

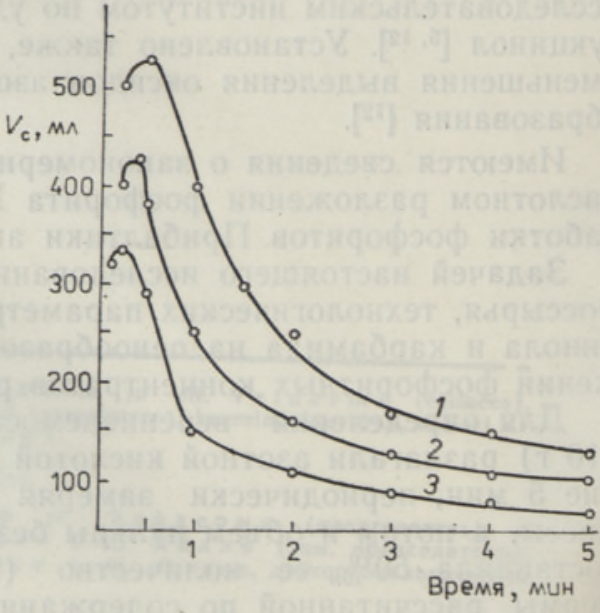

Рис. 2. Изменение объема реакционной смеси $\left(V_{\mathrm{c}}\right)$ при различных нормах $\mathrm{HNO}_{3}$ : $100(1), 80$ (2) и $60 \%$ (3). Навеска фосфорита $15 \mathrm{r}, \mathrm{C}-50 \%, T-50^{\circ} \mathrm{C}$. 
фосфорита. Образование пены начиналось вслед за дозированием фосфорита, и объем реакционной смеси $\left(V_{c}\right)$ достигал максимального значения (310-320 мл) по истечении 15 с. Разрушение пены происходило медленно и неполностью - остаточный объем реакционной смеси после 5-минутного перемешивания составлял еще 90-130 мл (объем пульпы без пены $17-20$ мл). Температура пульпы достигала $55-60^{\circ} \mathrm{C}$.

В условиях экспериментов максимальный объем пены $V_{\text {п }}$ (объем реакционной смеси за вычетом объема пульпы) составлял 293-303 мл. Указанные цифры значительно меньше расчетного количества смеси NO и $\mathrm{CO}_{2}$, выделяющейся при разложении пирита [15], фосфатного и карбонатных минералов. По-видимому, часть газов улетучивается в воздух или абсорбируется (NO) в азотнокислотной пульпе [16].

Установлено, что тонина помола фосфорита мало влияет на пенообразование. Например, при разложении маардуского фосфоритного концентрата снижение содержания фракции +180 мкм от 41,2 до 10,1\% вызывало увеличение максимального объема пены всего лишь на $3 \%$.

Эксперименты по азотнокислотному разложению кингисеппского фосфорита (таблица, образец 3) показали, что интенсивность пеновыделения существенно зависит как от технологического режима, так и от добавок. Например, при снижении нормы $\mathrm{HNO}_{3}$ от 100 до $60 \%$ (рис. 2) пены выделялось в 1,5 раза меньше и разрушалась она быстрее. В данном случае уменьшение пенообразования связано со снижением степени разложения как фосфатного вещества, так и железосодержащих минералов [5].

Со снижением концентрации $\mathrm{HNO}_{3}$ от 50 до $30 \%$ (рис. 3) максимальный объем пены возрастал приблизительно в 1,4 раза. При дальнейшем разбавлении кислоты (до 20\%) пеновыделение уменьшалось. Остаточный объем пены плавно снижался с уменьшением концентрации $\mathrm{HNO}_{3}$ во всем испытанном диапазоне.

Снижение температуры разложения от 70 до $35^{\circ} \mathrm{C}$ (рис. 4) приводило к замедлению пенообразования и уменьшению объема пены, однако стабильность пены возрастала.

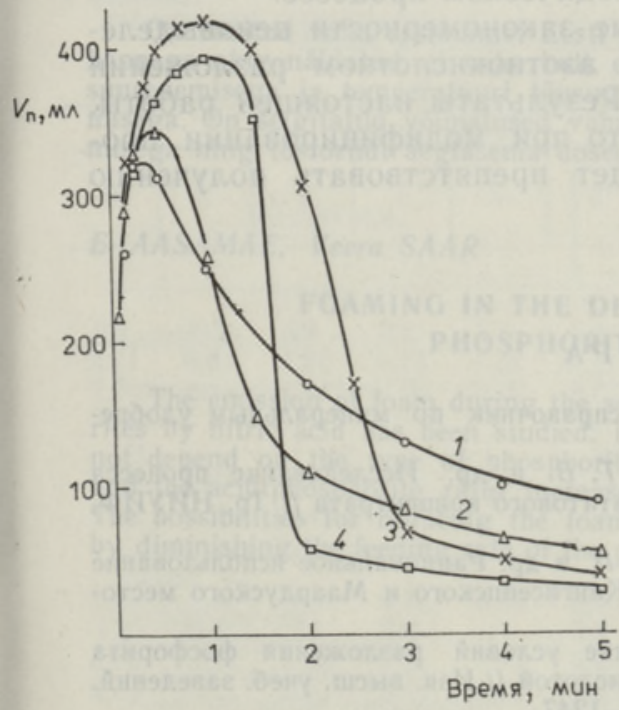

Рис. 3. Изменение объема пены $\left(V_{\Pi}\right)$ при различной концентрации $\mathrm{HNO}_{3}: 50$ (1), $40(2), 30$ (3) и $20 \%$ (4).

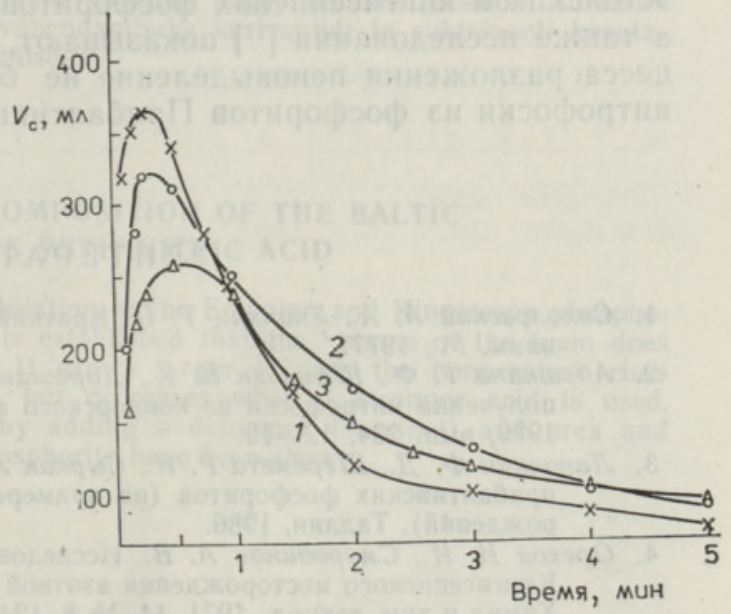

Рнс. 4. Изменение объема реакционной смеси $\left(V_{\mathrm{c}}\right)$ при различной температуре пульпы: 70 (1), 50 (2), $35^{\circ} \mathrm{C}(3)$. 


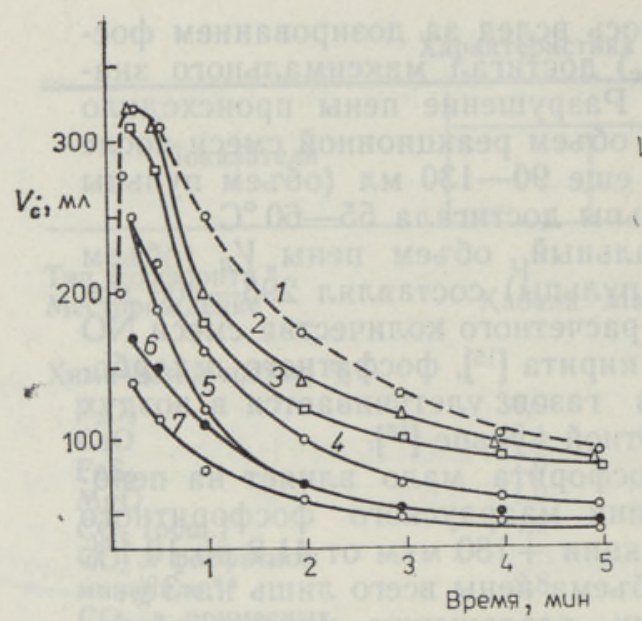

Рис. 5. Изменение объема реакционной смеси $\left(V_{\mathrm{c}}\right)$ при добавках карбамида в количестве 0,1 г $(2,6)$ и 0,2 г $(3,7)$, а также $5 \%$-ного раствора сукцинола в количестве 0,5 мл $(4,6)$ и 1,0 мл $(5,7)$. Кривая 1 - опыт без добавок.

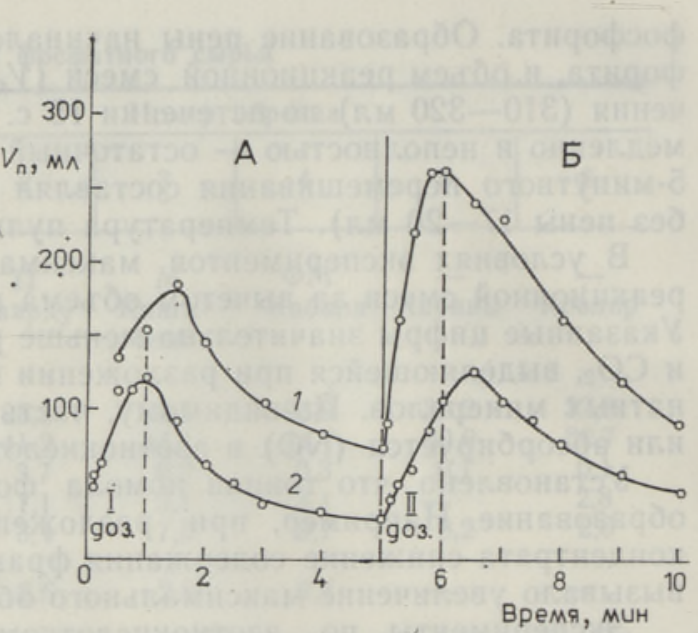

Рис. 6. Изменение объема пены $\left(V_{n}\right)$ при разовом (А) и повторном (Б) дозировании фосфорита без добавок (1) и с введением 0,2 г карбамида и 1 мл $5 \%$-ного сукцинола (2). Продолжительность дозирования 1 мин.

Добавка карбамида в количестве $1-2 \%$ от массы фосфорита (рис. 5 , кривые 2,3 ) снижала стабильность пены, введение же $5 \%$-ного водного раствора сукцинола (кривые 4 и 5) уменьшало как максимальную, так и остаточную вспениваемость в более значительной степени. Совместная добавка указанных реагентов (кривые 6 и 7) вызывала дальнейшее снижение максимального объема пены.

Пенообразование уменьшалось также с замедлением дозирования фосфорита (рис. 6, А). Эксперименты с повторной подачей фосфорита и $\mathrm{HNO}_{3}$ в пульпу, полученную из этих же видов сырья (рис. 6, Б), позволяют предположить, что при непрерывном процессе пеноразрушение будст происходить быстрее, чем при периодическом процессе.

Таким образом, установлены основные закономерности пеновыделения н гозможности его уменьшения при азотнокислотном разложении эстонских и кингисеппских фосфоритов. Результаты настоящей работы, а также исследования $\left[{ }^{17}\right]$ показывают, что при модифицировании процесса разложения пеновыделение не будет препятствовать получению нитрофоски из фосфоритов Прибалтики.

\section{Л И Т Е Р А Т У РА}

1. Соколовский A. А., Унанянц T. П. Краткий справочник по минеральным удобрениям. М., 1977.

2. Абашкина T. Ф., Шмульян E. К., Дорошина $T$. В. и др. Исследование процесса получения нитрофоски из ковдорского апатитового концентрата // Тр. НИУИФ, 1979, вып. 234, 12-19.

3. Ларичкин Ф. Д., Шеремета Р. И., Сыркин Л. Н. и др. Рациональное использование прибалтийских фосфоритов (на примере Кингисеппского и Маардуского месторождений). Таллин, 1986.

4. Орехов Н. И., Смородинов А. В. Исследование условий разложения фосфорита Кингисеппского месторождения азотной кислотой // Изв. высш. учеб. заведений. Химия и хнм. технол., $1971, \mathbf{1 4}$, № 8, 1246-1247.

5. Аасамяэ Э. Э., Вейдерма М. А., Кудрявщева Е. Н. Исследование азотнокислотного разложения тоолсеского фосфорита // Тр. Таллин. политсхн. ин-та, 1980, № 479, 3-11.

6. Позин М. Е. Технология минеральных солей. Л., 1970. 
7. Мальцева И. М., Перочинская М. Б., Абашкина Т. Ф. и др. Состав газовой фазы производства нитрофоски и пути уменьшения содержания вредных компонентов в ней // Тр. НИУИФ, 1979, вып. 234, 29-36.

8. Кудрявцева Е., Аасамяэ Э., Вейдерма М. Потери азотной кислоты при азотносернокислотном разложении фосфатного сырья // Изв. АН ЭССР. Хим., 1986, 35, № $1,1-6$.

9. Вейдерма М. А. Исследование процессов переработки оболовых фосфоритов в фосфорные удобрения и кормовые фосфаты. Автореф. докт. дис. Таллин, 1972.

10. Кудрявцева Е. Н., Аасамяэ Э. Э.; Вейдерма М. А. Влияние состава фосфатного сырья на его азотнокислотную переработку // Тр. Таллин. политехн. нн-та, 1983, № $542,11-23$.

11. Михеева Н. Е., Бочкарев $Г$. С., Гзовский А. С. Пеногашение в процессе получения экстракционной фосфорной кислоты из карбонатсодержащих фосфатов // Тр. НИУИФ, 1979, вып. 234, 121-128.

12. Аасамяэ Э., Вейдерма М. Влияние добавки карбамида на азотнокислотно-сульфатную переработку природных фосфатов // Изв. АН ЭССР. Хим., 1983, 32, № 1, $1-7$.

13. Кутфитдинов Р. Н., Усманова 3. Г. Исследование процесса пенообразования при азотнокислотной переработке карбонизированных фосфоритов Каратау // Физико-химические исследования синтетических и природных соединений. Самарканд, 1982, 70-74.

14. Аасамяэ Э., Вейдерма М. Оценка эстонских фосфоритных концентратов как сырья для кислотной переработки // Изв. АН ЭССР. Хим., 1983, 32, № 4, 242-245.

15. Арумээль Э., Кудрявцева $E$. О взаимодействии пирита с азотной кислотой // Изв. АН ЭССР. Хим., 1988, 37, № 3, 165-168.

16. Набиев М. Н. Азотнокислотная переработка фосфатов, I. Ташкент, 1976, 301.

17. Кудрявцева E., Аасамяэ Э., Вейдерма М. Получение нитрофоски из эстонских фосфоритов азотно-сернокислотным способом // Изв. АН ЭССР. Хим., 1987, 36 , № $2,93-97$.

Таллинский политехнический институт

Поступила в редакцию 26/IX 1988

\section{E. AASAMAEE, Veera SAAR}

\section{VAHUTAVUS BALTIKUMI FOSFORIITIDE LAGUNDAMISEL LAMMMASTIKHAPPEGA}

On uuritud vahu eraldumist Eesti ja Kingissepa fosforiitide lagundamisel lämmastikhappega ning näidatud, et vahu hulk ei olene fosforiidi tüübist. See kasvab happe hulga suurenemisega ja temperatuuri tõusuga, kuid väheneb happe kontsentratsiooni suurenemisega. On selgitatud vōimalused vahu vähendamiseks karbamiidi ja suktsinooli kasutamisega ning fosforiidi aeglasema doseerimisega.

\section{E. AASAMÄE, Veera SAAR}

\section{FOAMING IN THE DECOMPOSITION OF THE BALTIC PHOSPHORITES WITH NITRIC ACID}

The emission of foam during the acidulation of the Estonian and Kingissepp phosphorites by nitric acid has been studied. It is established that the volume of the foam does not depend on the type of phosphorite. It grows larger in case the temperature rises and the acid:phosphorite ratio increases, but decreases when a stronger acid is used. The possibilities for reducing the foam by adding a defoamer (succinol) and urea and by diminishing the feeding rate of the phosphorite have been shown, 